\title{
Improvements in Characterization of FIB Prepared Surfaces of Aluminum Using $\mathrm{Xe}^{+}$Plasma FIB
}

\author{
Brandon Van Leer ${ }^{1}$ and Rick Passey ${ }^{1}$ \\ 1. FEI Company, 5350 NW Dawson Creek Drive, Hillsboro, OR, USA
}

Critical to understanding the microstructure of aluminum and aluminum alloys is the careful surface preparation either by mechanical polishing or by ion beam techniques. Cross-section and S/TEM sample preparation of aluminium and aluminium alloys to characterize grain boundaries by focused ion beam (FIB) continues to be a major interest in metallurgical analysis because of FIB's ability to prepare site specific specimens while eliminating damage from mechanical polishing or electro-polishing [1]. However, gallium is particularly mobile in aluminium and known to diffuse along grain boundaries or interfaces, which can lead to embrittlement [2,3]. Often subsequent polishing in a broad beam polisher is a necessary step to improve the quality of the prepared surface for EBSD analysis. Also, characterizing large grain aluminum samples by $\mathrm{Ga}^{+} \mathrm{FIB}$ requires longer processing time when investigating multiple grains. Recent instrumentation using plasma FIB (PFIB) technology and $\mathrm{Xe}^{+}$ions offers an alternative ion species for FIB milling and increased milling rates because of its ability to deliver $30-40$ times more current compared to $\mathrm{Ga}^{+}$FIBs. While the measured sputter rate of aluminum using $\mathrm{Ga}^{+}$and $\mathrm{Xe}^{+}$differs by about $25 \%\left(0.31 \mathrm{~m}^{3} / \mathrm{nC}[\mathrm{Ga}]\right.$ and $\left.0.41 \mu \mathrm{m}^{3} / \mathrm{nC}[\mathrm{Xe}]\right)$, the ability to prepare gallium free thin sections for S/TEM analysis or large area cross-sections offers a solution to FIB milling artifacts seen with a $\mathrm{Ga}^{+}$ FIB as well as improving statistical analysis of grain populations.

Conventional cross-sections by FIB and S/TEM specimens of commercial grade 6061 T6 aluminum were prepared using the Helios G4 UX DualBeam ${ }^{\mathrm{TM}}$ using $30 \mathrm{kV} \mathrm{Ga}^{+}$ions and a Helios PFIB DualBeam using $30 \mathrm{kV} \mathrm{Xe}{ }^{+}$ions. Sample quality of the cross-sections were evaluated by comparing EBSD index rates and band contrast. Sample quality of the S/TEM specimens were evaluated by measuring FIB sidewall damage and observation of Ga contamination at grain boundaries in a Themis $\mathrm{Z}^{\text {TM }}$ TEM operating at 300 $\mathrm{keV}$.

A comparison of FIB sidewall damage between specimens prepared in $\mathrm{Ga}^{+} \mathrm{FIB}$ and $\mathrm{Xe}^{+} \mathrm{PFIB}$ revealed a decrease in sidewall by as much as $30 \%$ depending on the accelerating voltage applied. Figure 1 shows a SEM image the finished TEM lamellae of 6061 T6 aluminum as prepared in the Helios PFIB for FIB sidewall damage. Figure 2 shows a SEM image of a finished thin section of 6061 T6 aluminum across a grain boundary. EBSD results revealed that cross-section surfaces prepared with $30 \mathrm{kV} \mathrm{Xe}^{+}$PFIB had better band contrast results and improved indexing rates than cross-sections prepared with $30 \mathrm{kV} \mathrm{Ga}^{+} \mathrm{FIB}$.

\section{References:}

[1] L.A. Giannuzzi et al., Mater. Res. Soc. Symp. Proc. 480 (1997) p 19.

[2] K.A. Unocic et al., Journal of Microscopy 240 (2010) p 227.

[3] R.C. Hugo and R.G. Hoagland, Scr. Mater. 41 (1999) p 1341. 


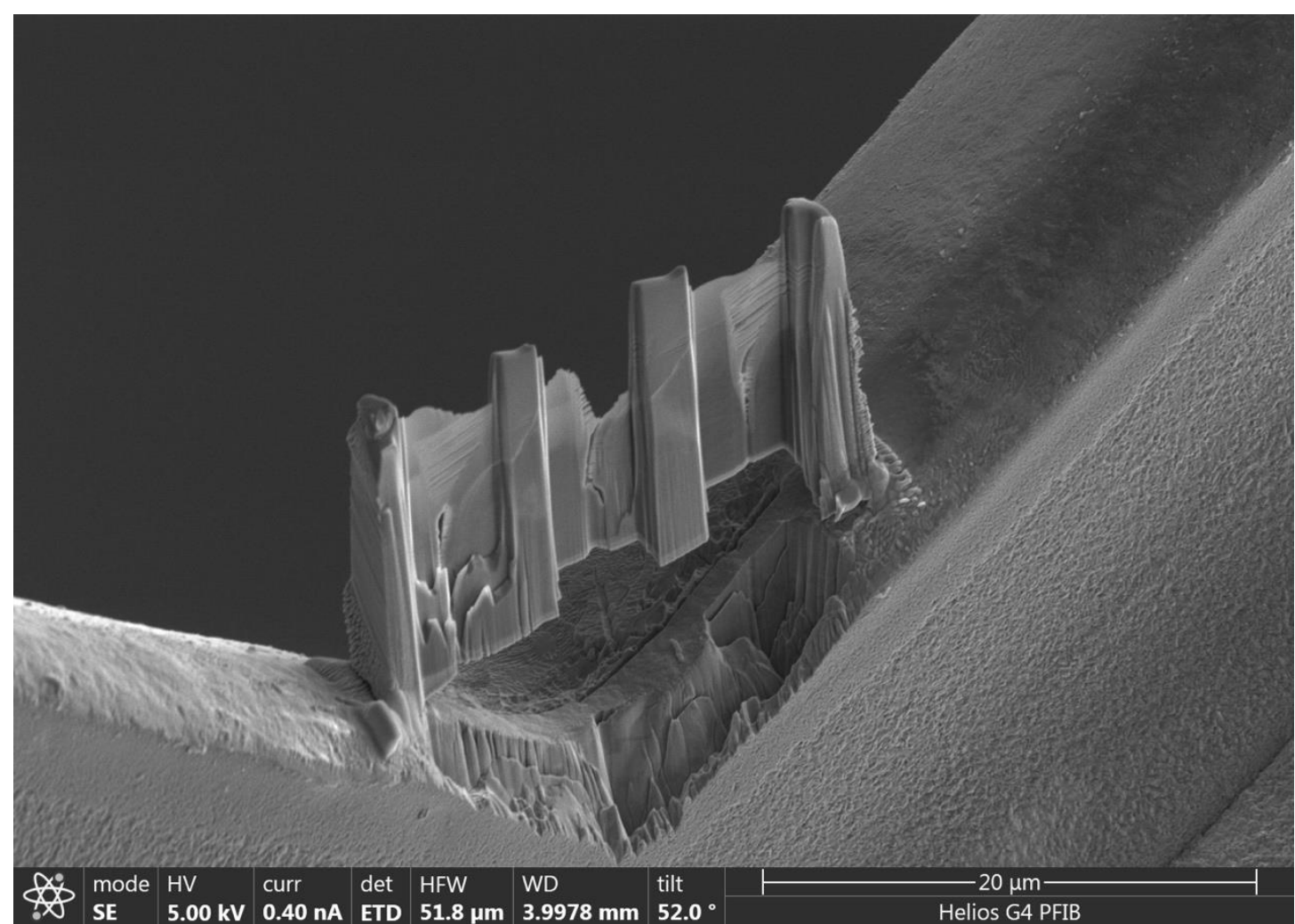

Figure 1. SEM image thin sectioned $6061 \mathrm{~T} 6$ aluminum characterizing the effect of accelerating voltage on FIB sidewall damage.

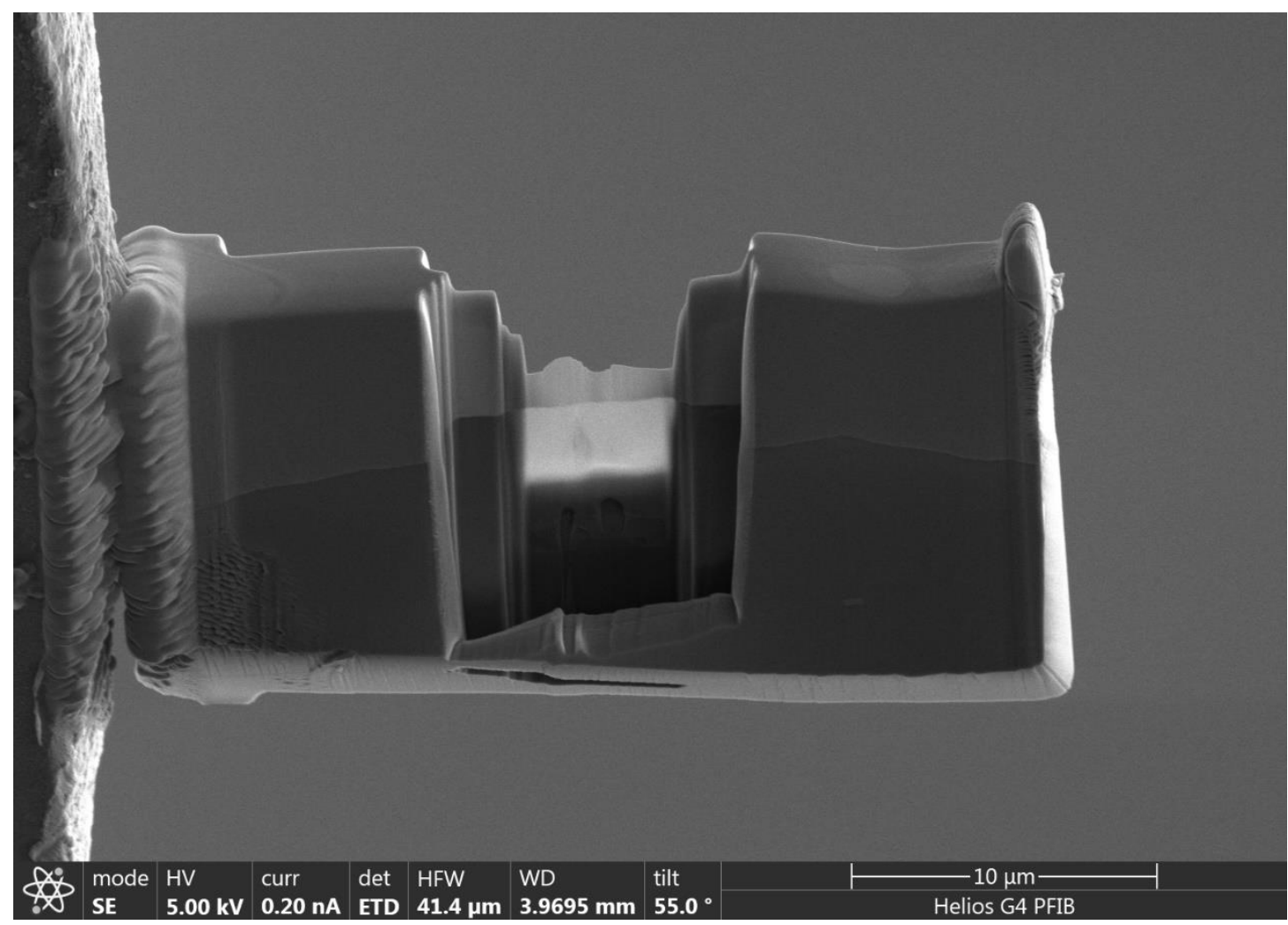

Figure 2. SEM image of thin sectioned 6061 T6 aluminum across a grain boundary. 